\title{
A DROGADICÇÃO NA ADOLESCÊNCIA CONTEMPORÂNEA ${ }^{1}$
}

\author{
Bianca Bergamo Savietto \\ Marta Rezende Cardoso
}

\begin{abstract}
RESUMO. Este artigo, fundamentado na Psicanálise, visa analisar a questão da drogadicção na adolescência contemporânea, mostrando quanto a dimensão de desamparo, com toda a complexidade que comporta, tem sido determinante no incremento deste fenômeno. Aborda o tema do desamparo tendo como pano de fundo uma instituição que, como outras instituições tradicionais, encontra-se hoje absolutamente enfraquecida e fragilizada: a família. É neste campo que os sujeitos adolescentes emergem e vêm a se desenvolver. Seria a drogadicção uma das respostas defensivas possíveis a essa situação de desamparo? Esta e uma das questões que norteiam o nosso percurso, no qual será também realizado um estudo da noção de transmissão psíquica, noção que nos permite estabelecer significativas relações entre os diversos elementos envolvidos na questão que nos ocupa.
\end{abstract}

Palavras-chave: drogadicção, adolescência, desamparo.

\section{DRUG ADDICTION IN CONTEMPORARY ADOLESCENCE}

\begin{abstract}
This paper, grounded on Psychoanalysis, aims at analyzing the issue of the addiction to drugs in contemporary adolescence, demonstrating how much the dimension of helplessness, with all its complexity, has been determinant in the current increase of this phenomenon. We'll study the theme of helplessness on the background of the family, one of the institutions that, along with the other traditional institutions, is totally weakened and frail; the adolescent subjects emerge and develop in this field. Is the addiction to drugs one of the possible defensive responses in front of this situation of helplessness? These are some questions that guide our route, in which we'll discuss the notion of psychical transmission, a notion that allows us establishing significant relations between the many elements involved in the issue we're studying.
\end{abstract}

Key words: Drug addiction, adolescence, helplessness..

\section{LA DROGADICCIÓN EM LA ADOLESCENCIA CONTEMPORÂNEA}

RESUMEN. Este artículo, fundamentado en el Psicoanálisis, busca analizar la cuestión de la drogadicción en la adolescencia contemporánea, mostrando hasta qué punto la dimensión de desamparo, con toda la complejidad que comporta, ha sido determinante en el incremento de este fenómeno. Abordaremos el tema del desamparo teniendo como telón de fondo una de las instituciones que, junto a las demás instituciones tradicionales, hoy se encuentra absolutamente debilitada y fragilizada: la familia; es en este campo que los sujetos adolescentes emergen y se desenvuelven. ¿Podría ser la drogadicción una de las respuestas defensivas posibles a esa situación de desamparo? He una de las cuestiones que orientan nuestro precurso, en el cuál también será realizado un estudio de noción de transmisión psíquica, noción que nos permite establecer significativas relaciones entre los diversos elementos involucrados en la cuestión que nos ocupa.

Palabras-clave: Drogadicción, adolescência, desamparo.

O presente artigo tem por objetivo analisar o tema da drogadicção na adolescência contemporânea.
Diante de uma geração de adolescentes na qual esse fenômeno se intensifica de forma assustadora, uma

1 Apoio: CAPES e CNPq.

* Psicóloga, Mestre em Teoria Psicanalítica. Doutoranda do Programa de Pós-Graduação em Teoria Psicanalítica do Instituto de Psicologia da UFRJ.

\# Psicanalista, Doutora em Psicopatologia Fundamental e Psicanálise, Professora Adjunta do Instituto de Psicologia da UFRJ (Programa de Pós-Graduação em Teoria Psicanalítica); Membro da Associação Universitária de Pesquisa em Psicopatologia Fundamental. Pesquisadora do CNPq. 
questão, para nós, ecoa: por que, entre esses adolescentes de hoje, o uso de drogas tornou-se tão intenso?

Certamente as respostas são múltiplas e complexas, e não pretendemos, evidentemente, esgotar a questão. Tampouco negamos o papel que certos aspectos da cultura contemporânea nela representam, como, por exemplo, o privilégio da esfera da ação em detrimento da dos pensamentos e da satisfação imediata em relação à espera. Vivemos numa cultura na qual o prazer é especialmente consagrado, resultando numa incessante busca de supressão da dor, o que incita, dentre outras saídas de caráter absoluto e imediatista, o uso abusivo de drogas. Sublinhemos, inclusive, que esta modalidade específica de resposta está diretamente articulada à procura incessante e ilimitada de prazer, diferentemente de outras situações clínicas de limite, também marcantes na atualidade, nas quais, porém, a questão da busca de prazer não se coloca. Escolhemos centrar o foco deste artigo na problemática da drogadicção na adolescência contemporânea em sua confluência com certos aspectos da estrutura familiar atual, campo no qual os sujeitos adolescentes emergem e vêm a se desenvolver.

Ao iniciarmos esta reflexão, uma condição já sobressai às demais, exigindo atenção de uma perspectiva tanto teórica quanto clínica: a vivência de desamparo. Ao longo deste trabalho, veremos quanto essa dimensão, com toda a complexidade que comporta, tem sido determinante no incremento do fenômeno da dependência de drogas na atualidade.

Analisaremos o tema do desamparo tendo como pano de fundo uma das instituições que, juntamente com as demais instituições tradicionais, encontra-se hoje absolutamente enfraquecida e fragilizada: a família. De que forma certas falhas e excessos que marcam a estrutura familiar contemporânea poderiam estar contribuindo para a intensificação do sentimento de desamparo nos sujeitos? Seria a drogadicção uma das respostas defensivas possíveis a essa situação de desamparo? Eis algumas das questões que vão nortear o nosso percurso.

\section{A NOÇÃO DE DESAMPARO}

Mário Costa Pereira dedica uma parte de seu livro Pânico e desamparo: um estudo psicanalítico (1999) à noção de desamparo originário. $\mathrm{O}$ autor afirma que, a partir do pensamento freudiano, a compreensão dessa noção ultrapassa em muito uma vertente biológica, isto é, não pode ser limitada à idéia de um estado de insuficiência psicomotora que seria própria ao bebê. Entender o desamparo sob uma ótica exclusivamente biológica significaria considerar o aparelho psíquico a partir de um ponto de vista evolucionista segundo o qual o desenvolvimento do psiquismo caminharia de um estado de dependência absoluta em relação a outrem para uma condição "madura", na qual a situação de desamparo viria a ser superada.

De acordo com esta visão reducionista, o desamparo não constituiria uma condição essencial e inevitável para o funcionamento psíquico. Se nos situamos, no entanto, numa abordagem psicanalítica, fundamentada na suposição de uma divisão psíquica no sujeito, a noção de desamparo vem nos remeter, em última instância, às possibilidades e aos limites da representação, de simbolização da força pulsional.

O desamparo vincula-se, então, de maneira intrínseca, à idéia de insuficiência: a princípio, insuficiência psicomotora do bebê, mas, em primeiro lugar, insuficiência do aparelho psíquico em dar conta do excesso de excitação (pulsional). O estado de desamparo é o protótipo de toda situação traumática, como Freud sustenta em Inibições, sintomas $e$ ansiedade (1926 [1925]/1976a), mostrando que se trata de um estado no qual o sujeito se vê inundado por um excesso de excitações, o qual ultrapassa a sua capacidade de ligação. De acordo com Joel Birman (2004), o que vem a permitir ao sujeito lidar com o pulsional, representá-lo, realizando o trabalho de ligação, de simbolização, situa-se no registro da ordem simbólica, implicando possibilidades de mediação, de contenção daquela força.

O mundo contemporâneo não se encontra especialmente amparado por essa ordem simbólica, mas se caracteriza, preferencialmente, pela precariedade, instabilidade, vulnerabilidade, incerteza e insegurança (Bauman, 2001); estamos, portanto, diante de uma carência de recursos de mediação. Do ponto de vista da constituição psíquica, o desamparo é inerente à subjetividade humana, em razão dos próprios limites do aparelho psíquico; mas é de perguntar: na contemporaneidade, dada essa fragilidade da ordem simbólica, não tenderia este estado a se impor na vida psíquica de modo exacerbado?

\section{O DESAMPARO NO SEIO DA FAMÍLIA CONTEMPORÂNEA}

Ao analisar o momento atual da sociedade ocidental, Zygmunt Bauman (2001) utiliza uma 
brilhante metáfora: a da "fluidez", ou "liquidez", Enquanto os sólidos possuem uma forma nítida, mantida com facilidade, os fluidos não apresentam dimensões espaciais rígidas, sendo então propensos a constantes mudanças.

Na modernidade, segundo o autor, teve lugar um processo de liquefação, de derretimento dos sólidos já estabelecidos, no sentido de um rompimento com o passado e a tradição. Bauman ressalta que este derretimento não deveria eliminar os sólidos de uma vez por todas, e sim, abrir espaço para "novos e aperfeiçoados sólidos” (Bauman, 2001, p. 9), dignos de confiança, que pudessem tornar o mundo previsível e administrável. Não obstante, a substituição dos antigos sólidos por novos que poderiam vir a constituir uma "solidez duradoura" (Bauman, 2001, p. 10) jamais se concretizou. Nesse processo de derretimento, a única ordem que parece ter se mantido foi a econômica. Pode-se dizer que instituições tradicionais como o Estado e a família, assim como padrões e configurações institucionalizados, "liquefizeram-se", adquirindo um caráter fluido, instável, volúvel, com forte tendência à mutabilidade.

Em relação à família, pode-se afirmar que o igualitarismo é a ideologia reguladora das novas relações familiares. Assim, de acordo com Sérvulo A. Figueira $(1987)^{3}$, autor atento às transformações ocorridas no seio da família, a tradicional "família hierárquica" - na qual os indivíduos são definidos a partir de sua posição, sexo e idade, havendo numerosas idéias sobre o "certo" e o "errado" - vai ceder o espaço (a partir da década de sessenta) para a nova "família igualitária". Sobre a identidade sustentada no âmbito da família igualitária, acrescenta Figueira que

homem e mulher se percebem como diferentes, pessoal e idiossincraticamente, mas como iguais porque indivíduos. As diferenças pessoais subordinam (e são percebidas como mais importantes que) as

2 As idéias de Bauman (2001) sobre o processo de liquefação ocorrido na modernidade também foram apreciadas no artigo Passagem ao ato e adolescência contemporânea: pais "desmapeados", filhos desamparados, de Bianca Bergamo Savietto (no prelo da Revista Latino-Americana de Psicopatologia Fundamental).

3 A análise desenvolvida por Figueira (1987) no trabalho $O$ "moderno" e o "arcaico" na nova família brasileira: notas sobre a dimensão invisível da mudança social também foi contemplada no artigo Passagem ao ato $e$ adolescência contemporânea: pais "desmapeados", filhos desamparados, de Bianca Bergamo Savietto (no prelo da Revista Latino-Americana de Psicopatologia Fundamental). diferenças sexuais, etárias e posicionais. Os sinais estereotipados da diferença homem / mulher tendem a desaparecer, se confundir ou se multiplicar, e os marcadores visíveis da diferença tendem, na medida do possível, a ser expressões do gosto pessoal. As noções bem delineadas de "certo" e "errado" perdem suas fronteiras, a noção de desvio de comportamento, pensamento ou desejo perde a clareza, e instaura-se, aparentemente, o reino da pluralidade de escolhas, que só são limitadas pelo respeito à individualidade do outro (Figueira, 1987, p. 16-17).

Sem perder de vista a metáfora da fluidez lançada por Bauman (2001), compreendemos que a solidez das posições ocupadas por cada membro da família, isto é, sua firmeza e estabilidade, também foi afetada pelo processo de derretimento, de liquefação. Deste modo, tanto na esfera da vida pública quanto na da vida privada, o sujeito contemporâneo depara-se com a ausência de autoridades rígidas, de regras e referenciais estáveis, encontrando-se imerso num contexto em que nada mais está "dado" e no qual ele é convocado a construir suas próprias referências, a elaborar as normas que regulam a sua existência.

Segundo Alain Ehremberg (2000), sociólogo francês que também se debruça sobre as implicações do contexto cultural contemporâneo na subjetividade, o fato de o indivíduo não estar mais sendo conduzido por uma ordem exterior, em conformidade com a lei, sendo "obrigado" a julgar por si mesmo, a contar apenas com seus recursos internos, acaba por resultar numa "doença da responsabilidade", em que a sensação que prevalece é a da insuficiência.

$\mathrm{O}$ sentimento contemporâneo de insuficiência levantado por Ehremberg remete-nos, uma vez mais, à noção de desamparo. Reiterando nosso objetivo de relacionar esse acirramento do vivido subjetivo de desamparo à particularidade da estrutura familiar contemporânea, faz-se necessário explorarmos melhor esse processo de fragilidade do poder e da ordem simbólica no contexto específico da família. Para tal, passamos a analisar, com mais vagar, o já mencionado processo de transformação da tradicional "família hierárquica" e a emergência da "família igualitária".

O modelo da família hierárquica, conforme esboçado acima, é aquele no qual existe, entre outros aspectos, uma relativa organização, um "mapeamento"; onde homem e mulher percebem-se como intrinsecamente diferentes, agindo de acordo com o que é tido como adequado a cada sexo. Pais e filhos também se relacionam ancorados na idéia da existência de "diferenças intrínsecas". A identidade na família hierárquica é definida por Figueira (1987) 
como posicional. Quanto às posições dos membros da família hierárquica, destacamos o lugar soberano que a figura de pai ocupa no indivíduo homem, sendo que na mulher tende a imperar o lugar de mãe e dona de casa. Além disto, vale também indicar outros aspectos próprios à família hierárquica, tais como uma conjugalidade reduzida ao casamento, um nãoreconhecimento de crianças nascidas fora dele e uma economia baseada na transmissão do patrimônio.

Em Généalogie de la morale familiale, Remi Lenoir (2003) também descreve - e com extraordinária riqueza - as mudanças operadas no cenário familiar. Dentre elas, o autor destaca as transformações relacionadas à escolarização e à profissionalização das mulheres (situadas por ele, na França, entre os anos 60 e 80, continuando até os dias de hoje - dados relativos a 1999) como geradoras de conseqüências ímpares sobre as formas de vida familiar. A ampliação do acesso das mulheres ao sistema escolar e ao trabalho assalariado teria produzido, como mostra o autor, uma profunda modificação no modo de vida das mulheres, antes centrado essencialmente no trabalho de integração familiar, considerado a partir de então "ultrapassado", "alienante", "limitado".

A ordem simbólica familiar vai sendo assim transformada, a repartição do trabalho de socialização, moralização e educação das crianças sendo redefinida, assim como o cuidado com os parentes idosos. A atividade profissional da mulher significou o desvio do trabalho desta (em parte considerável) do interior para o exterior do lar. Isto tudo representou um deslocamento tanto da posição feminina quanto da masculina em relação aos lugares antes ocupados na família hierárquica.

A prolongação da escolaridade trouxe também outros efeitos, como o adiamento de uma vida em casal estável (isto é apontado como sendo perceptível, na França, a partir dos anos 70) e o do nascimento do primeiro filho. A escolarização converteu-se na garantia de uma posição no espaço social, de modo que a formação do patrimônio dos lares passa a depender cada vez mais dela e menos diretamente da herança.

O crescimento da taxa de divórcios, de uniões livres, de naissances naturelles (isto é, nascimento de crianças fora do casamento), de famílias monoparentais, e a repartição dos papéis na família, as transformações das ligações entre gerações e dos modos de solidariedade familiar, são alguns dos aspectos tomados por Lenoir como indicadores do que ele vai denominar "renovação ética", "reforma moral", "obra de modernização moral". Alguns fatores são por ele apontados como de especial importância para a ocorrência dessa "renovação ética": a obtenção do direito de voto pela mulher, a reforma do divórcio, a afirmação (na Constituição) da igualdade entre os sexos e o reconhecimento do concubinato. $\mathrm{O}$ autor afirma, ainda, que os movimentos feministas, sem dúvida, contribuíram para dar visibilidade política e midiática às transformações da família.

Desenvolve-se, então, uma "nova moral doméstica", fundada sobre o princípio da autonomia das gerações e dos próprios cônjuges (Lenoir, 2003). Este princípio é generalizável, portanto, a todas as relações familiares, correspondendo à evolução dos modos de relação entre esposos, bem como entre pais e filhos.

Pensamos que esta família eticamente renovada, apoiada no princípio da autonomia, é a mesma família da qual fala Figueira (1987) quando se refere ao novo modelo familiar - a família igualitária - regulada pela ideologia do igualitarismo. Nesta família, que historicamente podemos considerar como contemporânea, a questão da hierarquia não se coloca, pois o poder encontra-se descentralizado.

Não obstante, a existência de novos ideais e identidades na família contemporânea não exclui a permanência de traços próprios à família tradicional. A este respeito, Figueira (1987) sublinha que a velocidade acelerada do processo de modernização da família acabou por resultar na aquisição de ideais e identidades que não vieram exatamente alterar os antigos, mas se sobrepuseram a eles. $\mathrm{O}$ autor utiliza o termo "desmapeamento" para descrever a presença simultânea de mapas distintos e contraditórios, asseverando - e este é um ponto que nos interessa especialmente - que o "desmapeamento" gera desorientação e conflito.

Levando em conta as modificações que tiveram lugar no espaço familiar, em particular a problemática da atomização do poder na família contemporânea e a conflitante sobreposição de mapas ordenadores tendo-se em vista a ressonância desses aspectos na subjetividade dos indivíduos sob a forma de uma radicalização da vivência de desamparo - levantamos a seguinte questão: tendo como pressuposto uma estreita articulação entre subjetividade e cultura, não poderíamos considerar que essas mudanças estariam exercendo papel considerável no incremento de certas patologias, mais precisamente, nos chamados estadoslimites? Nesse sentido, não consistiria o fenômeno da drogadicção, dentre muitas outras facetas, numa resposta extrema, por parte do sujeito, a um estadolimite de desamparo? Caberia, inclusive, ressaltar que a drogadicção, ainda que situada no campo dos estados-limites, possui especial relevo nesse contexto, 
na medida em que, ao implicar fortemente uma dimensão de transgressão da lei, vem revelar, de maneira bastante nítida, um processo de fragilidade do poder e da ordem simbólica da família contemporânea, de acordo com o que procuramos mostrar acima.

\section{IMPASSES DE UMA TRANSMISSÃO PSÍQUICA}

Visando aprofundar a idéia da existência de uma significativa imbricação entre certas características do modelo contemporâneo da família e o incremento do fenômeno da drogadicção entre os adolescentes, vamos nos deter neste momento num outro ponto que nos parece da máxima relevância: além da diluição das figuras de autoridade, a geração dos pais dos adolescentes atuais (a geração dos anos setenta - e fins dos anos sessenta, isto é, uma geração que viveu sua própria adolescência nesse período) vivenciou um processo de mudanças sociais cujo caráter foi particularmente radical. Essa geração veio a questionar intensamente o tradicionalismo de instituições como o Estado e a família, tendo assistido ao rompimento progressivo da ordem, das regras e das referências estabelecidas.

Vale a pena esclarecer que este aspecto está estreitamente vinculado à questão da diluição das figuras de autoridade. A vivência, por parte dos pais dos adolescentes de hoje, desse momento crítico da história da sociedade ocidental - no qual teve lugar um profundo processo de desestabilização - provocou nessas futuras figuras parentais um processo interno/externo de desorientação, com importantes implicações na assunção de seu papel de pais, tarefa que, para essa geração, parece ter se mostrado particularmente árida. Vemo-nos, assim, diante de uma problemática cuja dimensão é de transmissão assimilação de valores, do ponto de vista préconsciente-consciente, mas, antes de tudo, diante de um processo de transmissão psíquica, ou seja, transmissão, prioritariamente, de uma "herança" inconsciente.

A fim de melhor instrumentalizarmos a elaboração da questão central que nos ocupa - a drogadicção na adolescência contemporânea e sua relação com a fragilização do modelo da família passamos ao estudo de uma noção que é difícil de apreender, mas que acreditamos ser de grande valia para a nossa reflexão. Trata-se da noção de transmissão psíquica, que tem inegável relevo na teoria psicanalítica mas, dada a sua dificuldade, não deixa de ser também objeto de controvérsia nesse campo. Assim, antes mesmo de nos dedicarmos a uma pequena apreciação da noção, vejamos algumas pontuações apresentadas por René Kaës a propósito dessa controvérsia:

Com efeito, como aceitar a divisão estrutural desta (psique), que por muito tempo foi pensada como uma espécie de entidade monádica, e que extensão dar a essa hipótese, cuja consequiência extrema é a alienação do Eu na psique de um outro, de mais-de-umoutro? Como estabelecer a medida e o ritmo dessa tensão entre o que é da ordem do dentro dividido, e por isso constitutivo da realidade psíquica, e o que se manifesta na produção intersubjetiva da psique como uma condição decisiva de sua formação? Como conceber e tratar o sujeito como sendo "um fim para si mesmo", segundo a formulação de Freud, e herdeiro? (Kaës, 2001, p. 9).

Tratar do tema da transmissão psíquica significa lidar com a questão da herança. Na introdução do livro Transmissão da vida psíquica entre gerações, Kaës lembra aos leitores o interesse de Freud por esta temática. Em Totem e Tabu (1912-1913/1976b), a questão da herança arcaica da humanidade é representada pela culpa e pelos interditos transmitidos como efeito do assassinato do pai da horda primeva. Em "Sobre o narcisismo: uma introdução" (1914/1976c), Freud demonstra que o narcisismo do sujeito apóia-se no narcisismo da geração que o precede, ou seja, na transmissão à "Sua majestade, o beb̂e" de todos os desejos e fantasias não satisfeitas por seus pais. A partir dessa herança, o sujeito deverá subjetivar-se, isto é, apropriar-se do sentido de seu desejo próprio, assumir seu lugar.

Kaës afirma que esta perspectiva permite que se considere o sujeito do inconsciente como sujeito da herança. A transmissão da vida psíquica também é objeto de análise em "Psicologia de grupo e a análise do ego" (1921/1976d), onde Freud explora a questão pela via dos processos de identificação. Kaës considera que, em "Psicologia de grupo e a análise do ego", uma genealogia da psique é construída a partir da idéia de uma determinação, tanto intersubjetiva como intrapsíquica. Freud já havia construído o modelo da Segunda Tópica, e temos assim: "o Id hereditário, o Ego que deriva do Id, e o Superego herdeiro do complexo de Édipo e, portanto, do Superego dos pais" (Kaës, 2001, p. 11).

O sujeito do inconsciente, sujeito da psicanálise, não é determinado por aquilo que se opera no espaço intrapsíquico; ele não é, pois, "um fim para si mesmo". O sujeito do qual estamos tratando é também determinado por sua ligação com o campo da intersubjetividade, já que é precedido por sua família e 
por seu grupo, nos quais não escolhe ser incluído. $\mathrm{O}$ sujeito herda, portanto, uma bagagem da qual será necessário se apropriar. "Aquilo que herdaste de teus pais, conquista-o para fazê-lo teu".

Pergunta-se, não obstante: seria possível, para o sujeito, assimilar como próprio tudo aquilo que lhe é "implantado"? Seria possível metabolizar todos os elementos advindos do outro? Diversos autores vêm afirmando a frequiência com que percebem, na clínica atual - clínica marcada de maneira significativa pelos estados-limites - a impossibilidade de apropriação (e de transformação, portanto) da herança no processo de transmissão, o que revela a existência de uma dimensão, de uma espécie de identificação "em negativo" neste processo. ${ }^{4}$

Em nossa visão, a problemática da drogadicção na adolescência contemporânea também aponta - e de maneira particular - para uma dimensão "em negativo" no processo de transmissão, ou seja, para a impossibilidade de esses sujeitos integrarem, em seus psiquismos, a totalidade da herança recebida de seus pais. A presença de elementos "irrepresentáveis" no interior do sujeito produz um efeito, além de ruidoso, altamente "intoxicante", do qual ele pode, paradoxalmente, buscar se defender por meio da intoxicação pela droga. Em relação a este potencial do objeto, poderíamos considerar a drogadicção como uma experiência de construção de um escudo, de contenção à excitação desestruturante.

De acordo com Kaës (2001), a organização da transmissão parte da falha e da falta, porquanto, conforme apontado anteriormente, o narcisismo do sujeito tem como apoio a não-satisfação dos desejos e sonhos dos seus pais, isto é, do próprio narcisismo destes. No entanto, o aspecto que vem nos interessando destacar, em nossa busca de compreensão acerca do que vem sendo transmitido aos adolescentes atuais pela geração que os precede, é outro, de caráter mais radical. Trata-se daquilo que escapa à atividade de representação no processo de transmissão. Ou seja, algo é transmitido, já que “(...) nada do que foi retido poderá permanecer totalmente inacessível para a geração seguinte (...)" (Kaës, 2001, p. 17), mas não é capaz de fazer-se inscrever no psiquismo, sendo parte, desta forma, de uma herança intraduzível (os elementos intraduzíveis são "aqueles que o psiquismo não é capaz de metabolizar nem de recalcar." [Rezende Cardoso, 2002a, p. 87]), da qual não é possível apropriar-se. Esta parte permanece, então, como estrangeira no interior do psiquismo.

4 Este ponto foi amplamente explorado por Rezende Cardoso (2002) no seu livro Superego.
Podemos considerar que a drogadicção pressupõe a existência, no plano interno, de um objeto indiferenciado do eu, perigosamente alienante, intrusivo, dominador, intoxicante, do qual o adicto busca se defender por meio do apego a um pseudoobjeto controlável, e, mais especificamente, do qual o drogadicto busca desintoxicar-se, paradoxalmente, por meio da intoxicação pelas drogas. Entendemos que os impasses ligados ao processo de transmissão psíquica constituem a base do engendramento da presença deste objeto, responsável por uma intoxicação "primária", no interior do psiquismo do sujeito toxicômano.

Aquilo que se constitui como intraduzível no aparelho psíquico nos remete, segundo Kaës (2001), à idéia de um "não-trabalho" da transmissão psíquica. A noção de trabalho psíquico da transmissão, por sua vez, refere-se ao que é recebido e transformado, tornando possível para o sujeito o processo de apropriação da herança.

As pesquisas acerca da "negatividade" na transmissão vêm sendo desenvolvidas há cerca de 25 anos, instigadas justamente pela clínica dos casos ditos difíceis. Dois autores de indiscutível relevância no desenvolvimento desse tema - Nicolas Abraham e Maria Torok - elaboraram estudos sobre os efeitos do atravessamento geracional de segredos de família ("clínica do fantasma ou assombração"), abordando a impossibilidade do luto de um objeto significativo quando aliado a conteúdos indizíveis, os quais tendem a permanecer "encriptados" - poder-se-ia dizer, como enclaves - no psiquismo.

Os conceitos elaborados pelos dois autores são considerados “(...) conceitos-chave na clínica psicanalítica contemporânea (...)” (Ruiz Correa, 2000, p. 9). São conceitos-chave também em nossa reflexão, uma vez que estamos tentando burilar a hipótese segundo a qual o incremento da drogadicção na adolescência contemporânea poderia resultar do atravessamento geracional de um vivido traumático, aliado a inúmeros outros fatores.

Abraham e Torok procuraram traçar uma distinção essencial entre introjeção e incorporação. O processo de introjeção é aquele por meio do qual "o sujeito faz passar, de um modo fantasístico, de "fora" para "dentro", objetos e qualidades inerentes a esses objetos. (...) Está estreitamente relacionado com a identificação." (Laplanche \& Pontalis, 1982/1998, p. 248). O processo de introjeção implica, portanto, a possibilidade de assimilação do objeto (ou de elementos dele), de integração deste ao universo psíquico do sujeito. Olga B. Ruiz Correa (2000) afirma ainda que uma das características do processo 
de introjeção seria a de contribuir para o enriquecimento do eu. Essa autora também contribui para uma maior compreensão do conceito de incorporação descrito por M. Torok, indicando que este seria

(...) uma introjeção frustrada pela qual o objeto é incorporado no lugar do objeto perdido; o mesmo não contribui, porém, para uma ampliação do eu. Esse mecanismo está na origem de múltiplas repetições, agindo como detonador de um trabalho psíquico no deslocamento vinculado ao estado oral, já que o modelo de incorporação se origina na modalidade arcaica da ingestão (Ruiz Correa, 2000, p. 11).

A incorporação representa um processo no qual a mediação fantasística falha, uma vez que se trata de tomar o objeto (ou elementos dele) por uma via direta, sem transformação; tratar-se-ia de ser o objeto. Constatamos que o mecanismo de incorporação está, assim, articulado à existência de uma dificuldade ao nível do processo identificatório, já que a identificação pressupõe uma perda do objeto, um trabalho de luto que engendra a interiorização e a assimilação do objeto, de maneira integrada, no psiquismo do sujeito. A ligação entre transmissão psíquica e identificação é evidente. Jean José Baranes (2001) designou o "transgeracional" (transmissão da vida psíquica entre gerações) como o próprio princípio do processo de identificação (conforme mostra esse autor, isto se evidencia no caso do estabelecimento do superego).

Sem a intermediação da fantasia e, conseqüentemente, com uma não-transformação do objeto, o mecanismo de incorporação resulta numa interiorização deste sem assimilação, integração, propriedade sobre o objeto. Assim, o objeto assumirá o estatuto de estranho no interior do aparelho psíquico, que não consegue traduzi-lo, simbolizá-lo, incluí-lo em sua esfera representacional. Trata-se de algo que advém do outro e que permanece sendo "um outro" radical em si; ou seja, trata-se de um conteúdo recebido, herdado, mas do qual não é possível apropriar-se. O sujeito, então, herda-o, porém não $o$ conquista a fim de fazê-lo seu.

A não-lembrança está articulada àquilo que não possui representação, articulada - conseqüentemente, à falência dos mecanismos psíquicos mais elaborados. $\mathrm{O}$ que não é lembrado (porque não está representado) pode ser, no entanto, atuado. Num estudo sobre as desregulações narcísicas e objetais presentes, por exemplo, nos casos de bulimia, Philippe Jeammet vai pontuar que “(...) o comportamento atuado vem, justamente, substituir o trabalho de elaboração psíquica que sofre um curto-circuito." (Jeammet, 1999, p. 113). A partir de todas essas afirmações, concluímos que, uma vez presentes no aparelho psíquico, os elementos "irrepresentáveis", apesar de não simbolizados, produzem ruidosos efeitos.

\section{DROGADICÇÃO E O "INTRADUZÍVEL"}

Conforme temos procurado indicar, a drogadicção pode ser considerada, dentre outros aspectos, como uma possível resposta do sujeito à presença perturbadora, em seu psiquismo, de elementos intraduzíveis, inassimiláveis (um possível efeito dessa presença que, não passível de representação, demanda atuação). Estes elementos representariam uma dimensão "em negativo" do processo de transmissão, uma herança da qual o sujeito não se apropriaria. $\mathrm{O}$ psiquismo, submetido à pressão dessa herança "maldita", da insistência, desde o interior, do traumático, de um excesso pulsional não dominável estado de passividade, de desamparo, portanto - pode tentar reverter tal situação por meio de uma atuação, geralmente, de caráter transgressivo (no sentido fundamental de um atravessamento). O corpo tende a ser convocado - registro do ato - exatamente quando o psiquismo não consegue dar conta, não é capaz de ligar o excesso pulsional.

Ao analisar a questão da violência, Marta Rezende Cardoso (2002b) utiliza uma metáfora que em muito pode iluminar a compreensão das atuações dentro dessa perspectiva de uma tentativa de domínio do excesso pulsional. No lugar de associar o termo transgressão diretamente a uma dimensão própria à lei e à castração, como freqüentemente se tende a fazer, a autora inspira-se na expressão "transgressão marinha" - "que consiste no "movimento das águas do mar, ao invadirem um trecho do continente" (Rezende Cardoso, 2002b, p. 161) - para analisar a invasão da força pulsional, sua face não ligada, no território egóico. O mecanismo da passagem ao ato consistiria, então, numa resposta (por mais primária ou elementar que seja) a essa transgressão, a esse transbordamento pulsional no espaço egóico.

Não envolveria o fenômeno da drogadicção essa dimensão de ato transgressivo (aqui também no que se refere à lei) no sentido de uma tentativa de dominação do ataque pulsional? Muitas vezes, a impossibilidade de representação desse excesso faz-se sentir, paradoxalmente, como um vazio. Trata-se aqui da nossa tentativa de operar uma positivação da 
compreensão acerca desse sentimento de vazio, à medida que este está referido, na verdade, a um "cheio"; um "cheio" pulsional, no sentido de uma "impressão" irrepresentável. A sensação de vazio, por ser intolerável, pode levar o sujeito a uma tentativa de preenchimento com a droga. Nas palavras de Hugo Mayer:

A droga vem assim ocupar o lugar dos pais faltantes; da mãe em sua função de sustentação que, ao menos momentaneamente, oferece a sensação de evitar cair num vazio abismal; do pai, como organizador central de uma cultura que concede um lugar de identificação, de pertencimento e de confronto. (Mayer, 1997, p. 87-88; Tradução nossa).

Buscar-se-ia igualmente na droga uma sensação de bem-estar e proteção que não se poderia obter mais nas relações familiares? Segundo Mayer, os modelos enfraquecidos de homem e mulher, de pai e mãe, dificultam em muito os caminhos identificatórios, alimentando a angústia, a incerteza e uma "primarização" dos afetos, o que, a nosso ver, vem a conduzir o ego a fazer uso de defesas elementares, tais como as que estão em jogo no fenômeno da drogadicção.

Uma das possibilidades do ego diante da violência psíquica é buscar reverter, também de forma violenta, a passividade em atividade, o que leva ao ato, dimensão claramente presente na clínica contemporânea. As atuações são quadros considerados limites justamente por apontarem as fronteiras de representabilidade de um conflito no espaço psíquico.

\section{CONCLUSÃO}

À guisa de conclusão, gostaríamos de acrescentar que, diante dos aspectos aqui levantados, poder-se-ia pensar que o pessimismo é o único sentimento possível. No entanto, abordando a intensificação da violência na contemporaneidade, Birman (2004) nos lembra que, apesar de desejar a paz, Freud mostra que "a guerra é uma possibilidade sempre presente no horizonte social e histórico" (Birman, 2004, p. 9). É a qualidade das relações entre pulsão de vida e pulsão de morte, no registro psíquico, que vem delinear as condições de possibilidade da guerra e da paz no registro intersubjetivo. Ambas as pulsões estão sempre presentes, variando a proporção e a organização de sua relação.

Lembremos, também, que o processo de criatividade não pode abdicar da participação privilegiada da ação excessiva da pulsão de morte. Afinal, como construir o novo sem destruir o já existente? É legítimo que esperemos, portanto, que o caos atual não redunde no apocalipse, e sim, que possamos assistir ao incremento de uma tão esperada ordem simbólica.

\section{REFERÊNCIAS}

Baranes, J. J. (2001). Tornar-se si mesmo: avatares e lugar do transgeracional. Em R. Kaës, H. Faimberg, M. Enriquez \& J. J. Baranes, Transmissão da vida psíquica entre gerações (pp. 191213). São Paulo: Casa do Psicólogo.

Bauman, Z. (2001). Modernidade líquida. Rio de Janeiro: Jorge Zahar.

Birman, J. (2004). Violence, ségrégation et formes de subjectivation. Ensaio escrito a partir das notas que orientaram a apresentação oral realizada na mesa redonda intitulada "Temps et Mesure", no Congresso Internacional de Psicanálise do Espaço Analítico, em 7 de Março de 2004, em Paris. (Mimeografado).

Costa Pereira, M. E. (1999). Pânico e desamparo: um estudo psicanalítico. São Paulo: Escuta.

Ehremberg, A. (2000). La fatigue d'être soi. Paris: Odile Jacob.

Figueira, S. A. (1987). O "moderno" e o "arcaico" na nova família brasileira: notas sobre a dimensão invisível da mudança social. Em S. A. FIGUEIRA (Org.), Uma nova família? O moderno e o arcaico na família de classe média brasileira (pp. 11-30). Rio de Janeiro: Jorge Zahar.

Freud, S. (1976a). Inibições, sintomas e ansiedade. Em Jaime Salomão (Ed. e Trad.), Edição Standard Brasileira das Obras Psicológicas Completas de Sigmund Freud (Vol. XX, pp. 107-201). Rio de Janeiro: Imago. (Original publicado em 1925-1926).

Freud, S. (1976b). Totem e tabu. Em Jaime Salomão (Ed. e Trad.), Edição Standard Brasileira das Obras Psicológicas Completas de Sigmund Freud (Vol. XIII, pp. 20-191). Rio de Janeiro: Imago. (Original publicado em 1913-1914).

Freud, S. (1976c). Sobre o narcisismo: uma introdução. Em Jaime Salomão (Ed. e Trad.), Edição Standard Brasileira das Obras Psicológicas Completas de Sigmund Freud (Vol. XIV, pp. 89119). Rio de Janeiro: Imago. (Original publicado em 1914).

Freud, S. (1976d). Psicologia de grupo e a análise do ego. Em Jaime Salomão (Ed. e Trad.), Edição Standard Brasileira das Obras Psicológicas Completas de Sigmund Freud (Vol. XVIII, pp. 91179). Rio de Janeiro: Imago. (Original publicado em 1921).

Jeammet, P. (1999). As condutas bulímicas como modalidade de acomodação das desregulações narcisistas e objetais. Em R. Urribarri (Org.), Anorexia e bulimia (pp. 113-136). São Paulo: Escuta.

Kaës, R., Faimberg, H., Enriquez, M., \& Baranes, J. J. (2001). Transmissão da vida psíquica entre gerações. São Paulo: Casa do Psicólogo.

Laplanche, J., \& Pontalis, J. B. (1982/1998). Vocabulário da psicanálise. São Paulo: Martins Fontes.

Lenoir, R. (2003). Généalogie de la morale familiale. Paris: Seuil.

Mayer, H. (1997) Adicciones: Un mal de la posmodernidad. Buenos Aires: Ediciones Corregidor. 
Rezende Cardoso, M. (2002a). Superego. São Paulo: Editora Escuta.

Rezende Cardoso, M. (2002b). Violência, domínio e transgressão. Aceito em 08/07/2008 Psychê, VI(10), 161-171.

Ruiz Correa, O. B. (2000). Os avatares da transmissão psíquica geracional. São Paulo: Escuta.

Endereço para correspondência :

Marta Rezende Cardoso, Rua Gustavo Sampaio, 710 / 1805, CEP 22010-010, Rio de JaneiroRJ, Brasil.E-mail: rezendecardoso@ig.com.br 